\title{
Value and price: a transdisciplinary approach to urban water management
}

\author{
K. Kviberg \\ School of Geography Geology and Environmental Science, \\ University of Auckland, New Zealand
}

\begin{abstract}
This paper puts forward the benefits of a transdisciplinary approach to environmental management, using urban New Zealand use and value of freshwater as a case study. New Zealand is not water poor, but suffers from regional seasonal stresses on freshwater resources. The old mindset that water is a free gift from nature prevails within the water management industry, encouraging unsustainable consumption behaviours that are likely to develop into significant economic dis-benefits. Existing pricing structures are obscuring signals of both water shortages and wasteful practices, raising concerns that New Zealand urban water is underpriced and undervalued. The paper aims to fit a transdisciplinary research framework, drawing from economic, social and environmental disciplines, to establish options for resource management and asset investment. By the coupling of values with consumption, and the willingness to pay for environmental goods and services, this framework maximises environmental and welfare objectives aligned with sustainable development goals.
\end{abstract}

Keywords: choice modeling, low-impact urban design, pricing, transdisciplinarity, values, water management.

\section{Introduction}

Improved understanding of the interconnectedness in nature and the complexities of environmental problems emerged at an increasing rate throughout the second half of the last century [1-3]. The deficiencies of discipline-based research in dealing with these problems has become increasingly evident, resulting in the 
coordination of multi-disciplinary research teams, inter-disciplinary research projects, as well as the transdisciplinary approach [4-8].

It has been suggested that the uptake of transdisciplinary research will better address the complex socio-environmental problems currently undermining sustainable development efforts $[4,6,9]$. Transdisciplinary research is not antagonistic but complimentary to disciplinary, multidisciplinary and interdisciplinary research. It is seeking to understand the workings of whole systems as they exist, as opposed to producing knowledge of their constituent parts, which is aptly provided for by each discipline [6]. In accordance with systems theory, it views a system as being more than its constituent parts, and that sustainable solutions come from the synergy of disciplinary methods. A transdisciplinary framework needs to be cost-effective, socially acceptable, with transparent responsibilities and accountabilities. Transdisciplinary activities include problem definition, problem representation and problem solving [9].

Water is a perfect example of a sustainable development challenge encompassing environmental, economic and social dimensions. Reconciling these three aspects is a significant policy challenge for governments [10]. Water is a unique raw material, essential for life, economic activity, and cultural identity. Global trends show a quadrupling in water demand due to industrialisation and irrigation and a decline in available water supplies by $40 \%$ since 1970; an increase in costs relating to more distant and poorer water quality supplies; with a corresponding increase in energy consumption to meet water demands [11, 12]. Freshwater, once considered the ultimate renewable resource, is currently utilised in terms of both take and degradation at a rate exceeding the rate of natural replenishment on a global scale. The old mindset that water is a free gift from nature continues to encourage squandering of the resource. Current management of freshwater resources in New Zealand cities is unsustainable and likely to develop into significant economic dis-benefits on regional and national scales [13].

This paper posits that a transdisciplinary approach may assist management practices better aligned with sustainable development goals. It is structured under the main components of transdisciplinary research: problem definition; problem representation and problem solving.

\section{Problem definition: current management practice}

Originating from the experience of health benefits as a result of improved sanitation in the mid to late 1800's, the "big-pipe-in big-pipe-out" centralised water management strategy has been the norm in almost all industrialised cities for the last 150-200 years [14]. The designs of these systems reflect the general paradigm related to natural resources of the time; considering water a gift from nature and assuming free disposal of polluted water to the environment. With urban centres reaching the size they are today and with continued rapid growth; this approach has become a classic example of Hardins' "tragedy of the commons" [15]; the over-extraction in water-scarce regions, and the degradation of urban streams and harbours in wetter regions. Community perceptions and the 
willingness to accept policy change is poorly understood in most water management districts. This commonly prohibits the implementation of technological and policy improvements, affecting asset investment decisions and thus continues to foil attempts to create sustainable, low impact urban communities.

\subsection{Social}

How resources are managed depends upon a society's perception of value. This may change with an improved understanding of management options and subsequent consequences for the economy, society or the environment. Thus, imperative to sustainability is the continuous evaluation of community attitudes and expectations with regards to resource management, and mapping of divergent interests to deal appropriately with stakeholder conflicts [16]. Only by knowing these multiple realities can one design policies that, whilst deemed acceptable, pull communities' behaviours away from wasteful consumption towards ecologically sustainable resource utilisation and asset investment.

The implementation of large scale demand management strategies have consistently demonstrated that technological fixes alone can not adequately address issues of urban freshwater management [17-21]. Evidence is emerging that there is support for demand management to be utilised to its full potential, and that pricing structures/adjustments are favoured over water rationing both in New Zealand and other countries [22-27].

Effecting behavioural changes demand that stakeholders (or problem owners/ water consumers) take responsibility for the environmental effects of their actions. Kolokytha et al [18] and Nancarrow et al [19] explored the relationship between how people perceive themselves as water consumers and consumption behaviour. Both studies found that how consumers valued water did not significantly affect consumption behaviour. These results indicate a present decoupling of values and environmental behaviours.

\subsection{Economic}

The traditional economic approach to infrastructure development considers water a public good funded in full by governmental agencies. However, shifting trends in water pricing in OECD countries have seen an increase in the use of full costrecovery pricing structures, and an increasing use of volume based charges [10]. It is considered that this shift has contributed to a stabilisation of demand, or in some European cities, net reductions in demand [28]. Urban water supply contains two major components of cost: infrastructure and storage, and supply operations. The cost recovery process likewise entails two components, one to cover the investment in infrastructure assets, and the other the marginal cost of water use [24, 29]. Scarcity and/or ecological externalities on the other hand are commonly not factored into the pricing equation. Charges for water are typically set by local utility operators owned or subsidised by local government and are charged either through the general rating structures, or by volume, with an additional fixed charge component. Such pricing structures for urban water supplies prevent signals of water shortages and encourage wasteful practices 
raising concerns that urban water is both under-priced and under-valued, with cross-subsidies commonly obscuring signals of the real value of water [13].

Social equity concerns are often, and justifiably, contentiously argued in the water pricing debates. The established benchmark affordability level for household water and sanitation expenditure is set at $4-5 \%$ of the household income [10]. On average, residents in New Zealand cities spend $2 \%$ or less for water and sanitation, and thus can afford to squander the resource.

Allocation of water resources is rapidly becoming a significant issue in Christchurch, New Zealand's third largest urban centre, where potable supplies and urban streams both originate from high quality aquifers. Abstraction for urban supplies has caused diminished water-flows in streams, affecting both ecological and recreational values. The community's willingness to pay for the retention of flows in Christchurch streams has been found to be relatively high, suggesting that some New Zealand communities readily accept that environmental protection has benefits [25]. Whether this is reflected in a willingness to change behaviour, or merely suggesting an acceptance of importing water from rivers further a field has not been subjected to research.

\subsection{Cultural}

Water is a unique raw material, not only essential for life and economic activity, but also people's cultural identity. Recreation, amenity values and the spiritual connections to water is by current management practise decoupled from people's perceptions of the value and willingness to pay for water in the city.

The New Zealand cultural perspective is unique. Maori, New Zealand's indigenous people, proclaim a special relationship with water and have inherent strong 'views' on, and are sensitive to, water management practises and the protection of mauri (life-force) [13]. It has been suggested that to meet sustainability objectives, infrastructure services need be provided in a way that protects cultural heritage values, give due consideration to customary interests in natural resource use, and allow participation of Maori as partners in decisions regarding natural resources [30].

\section{Problem representation: segregation}

How do these aspects interlink into one system? For urban water management to be sustainable it must be integrated across management fields and consider potable water, stormwater, wastewater and natural water bodies as part of one system. This approach requires the integration of built form into the strategic planning, as well as demand management and water recycling schemes across several scales [31]. Barriers to such integration remain amongst water industry managers, policy makers and the consumer community at large.

Figure 1 shows a segregated, linear urban water management system. Stormwater, potable water and natural water bodies are commonly managed by isolated entities. The clear boxes show components where New Zealand water management is currently lacking in technological and/or policy implementation and asset investment. Thus, these inactive elements do not influence price, nor 
do they allow pricing to be an instrument for demand management as a response to physical stocks.

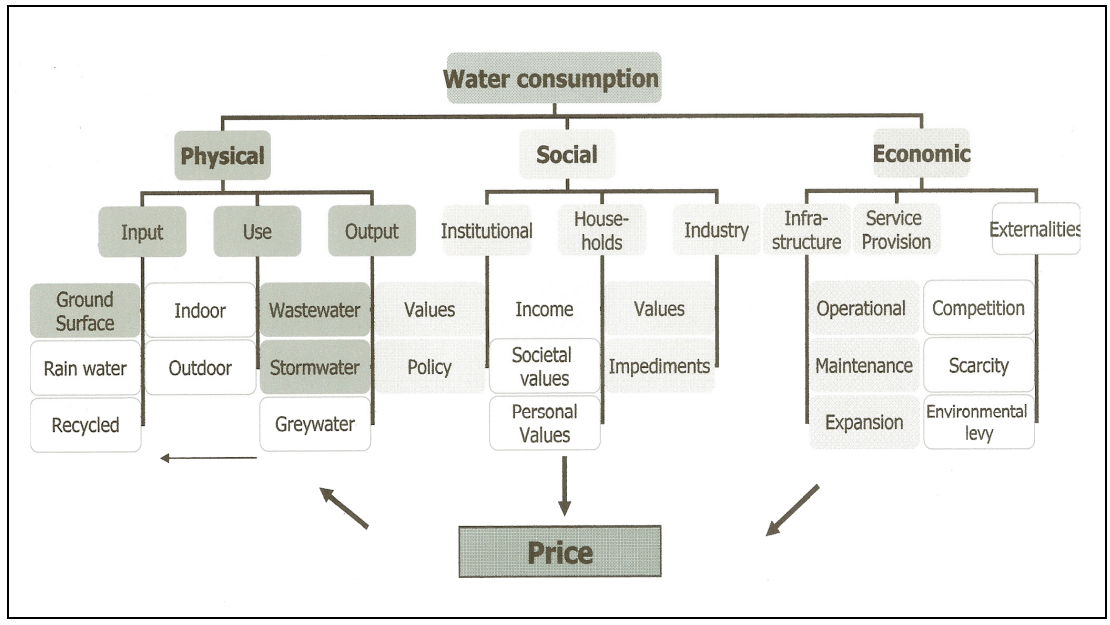

Figure 1: Urban water consumption.

\section{Problem solving: coupling values and price}

This paper purports addressing unsustainable urban water management trends through a framework that draws from the disciplines of urban ecology, resource economics, ecological economics, engineering, water industry and planning/policy science from a values perspective. Figure 2 shows this transdisciplinary framework for the urban water management sector including components at four cognitive levels, and illustrates the broad range of management fields that need to be included (as opposed to consulted with) as stakeholders in a holistic water management system.

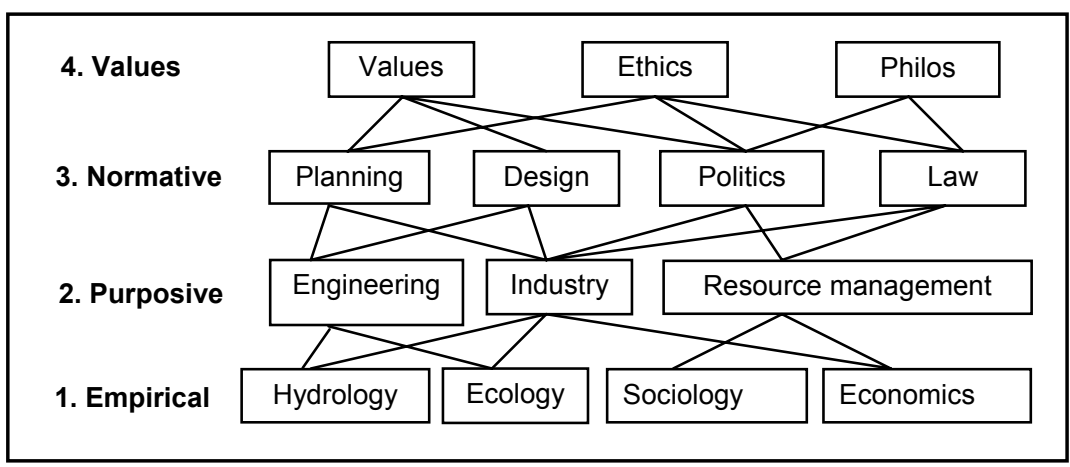

Figure 2: A transdisciplinary framework for urban water management (Adapted from [5]). 
The role of a transdisciplinary researcher would be to facilitate the inclusion of methodologies from these fields, to map divergent interests, to promote synergy and learning between and within each participant, and to devolve responsibilities and accountabilities.

The construction of a transdisciplinary framework that 1) identifies consumer barriers to technical fixes such as greywater recycling and rainwater collection and use (reducing polluted runoff to streams and stormwater treatment expenses); 2) identifies and quantifies the willingness to pay for environmental goods and services (consumer surplus); and 3) identifies the perceived values of water; should enable the water management industries to remove barriers, to couple the consumer surplus with the perceived values and thus allow asset investment to be ecologically as well as economically efficient.

\section{Discussion}

A transdisciplinary framework aligning urban water pricing policy with sustainable development objectives should include performance indicators of current water management practises against ecological sustainability indicators; a pricing structure for urban water that promotes sustainable resource use; and a strategy for enhancing public perception and value of water to encourage the acceptance of a pricing structure supporting desirable economic, environmental and social outcomes.

\subsection{Value and price}

The discrepancy between communities' values and perceptions on one hand and urban water consumption behaviour on the other can be explained by the decoupling of water as an ecological good, and water as an economic good (Figure 3). Analyses of consumers' understanding of pricing policies and their willingness-to-pay response to alternative pricing structures could clear the way for incorporating an extended subjective utility function accounting for ecological values and ecologically sustainable water service provision. A costbenefit analysis based on such a function is likely to support the investment in decentralised, water-shed based reticulation models for low impact urban design.

This would in turn allow resource managers to develop pricing policies reflecting the ecological values of water.

If ecological sustainability is a goal for society, policies must be developed that allow ecological rents into the traditional pricing equation. By asking the community how much more they would be willing to pay for water if the price included resource protection and conservation measures would assign value to the resource, and be used to assign value to behavioural changes, encouraging community responsibility and accountability.

\subsection{Sustainable decision making}

Conventional cost-benefit analysis (CBA) allows choosing a policy alternative among others on the criterion of economic efficiency. The use of multi-criteria 
analysis (MCA) has increased significantly in the last two decades as an attempt to satisfy often conflicting objectives of multiple stakeholders in decision making [32]. Holz et al [33] point to some of the limitations of CBAs and MCAs, and posit bridging the dichotomous "calculate or communicate" divide by the structure of a framework drawn from both approaches.

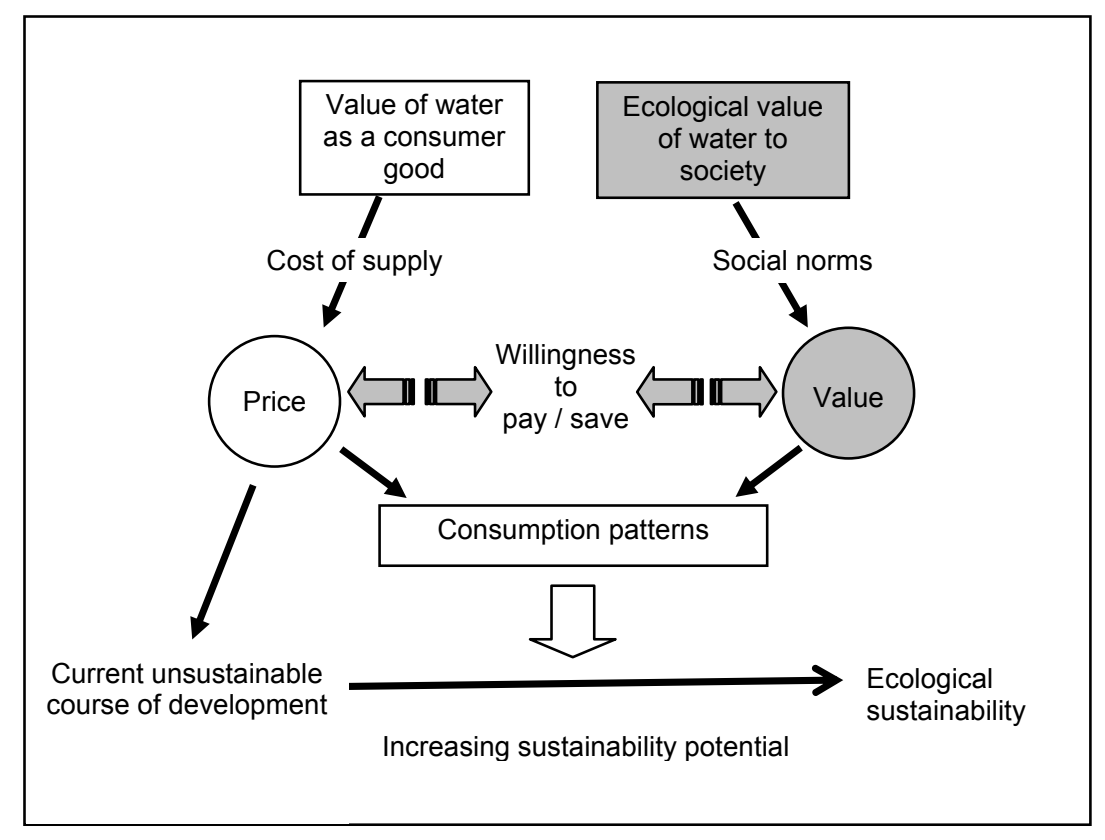

Figure 3: Relationship between values, price and consumer behaviour.

One approach to policy analysis in a transdisciplinary framework is the use of system dynamics modeling. System dynamics models the interactions of population, ecological and economic systems using feedback loops [34]. Stocks and flows connections are used to run "what if" simulations to test certain policies, and can as such greatly aid managers and communities in understanding how the system changes over time $[35,36]$.

Effecting behavioural changes demand that consumers take responsibility for the environmental effects of their actions. This needs to be facilitated by policies aimed at encouraging environmentally responsible behaviour. The benefits of using a transdisciplinary approach to assess current and alternative water management, investment and pricing policies include the capacity to couple choice modeling with system dynamic modeling, allowing consumers to visualise the consequences of management options aiding in assigning value to behavioural changes. 


\section{References}

[1] Ehrlich, P.R. \& Ehrlich, A.H., Why isn't everyone as scared as we are? (Chapter 1). Valuing the earth: economics, ecology, ethics, eds. H.E. Daly \& K.R. Townsend, Massachusetts Institute of Technology Press: Cambridge, pp. 55-67, 1993.

[2] Meadows, D.H., Meadows, D.L., Randers, J. \& Behrens, I.W.W., The limits to growth, Universe Books: New York, 1972.

[3] Odum, E.P., Fundamentals of Ecology, W. B. Saunders, Comp.: Philadelphia, 1953.

[4] Becker, E., Transformation of social and ecological issues into transdisciplinary research. Knowledge for Sustainable Development: An Insight into the encyclopaedia of life support systems, UNESCO / Eolss Publishers: Paris, Oxford, 2002.

[5] Max-Neef, M.A., Foundations of transdisciplinarity. Ecological economics, 53(1), pp. 5-16, 2005.

[6] Nicolescu, B., The transdisciplinary evolution of the university condition for sustainable development, Universities' Responsibility to Society, Centre International de Recherches et d'Etudes Transdisciplinaires (CIRET): Bangkok, 1997.

[7] UNESCO, Conference on science and tradition: transdisciplinary perspectives on the way to the 21 st Century-1991,

www.transdcongress.com.br/interna.. sp ?idCliente $=83 \&$ acao $=$ materia\&id $=$ 5850

[8] World Commission on Environment and Development (WCED), Our common future, United Nations: Oxford, 1987.

[9] Sholtz, R.W., Mieg, H.A. \& Oswald, J.E., Transdisciplinarity in groundwater management- towards mutual learning of science and society. Water, Air, and Soil Pollution, 123, pp. 477-487, 2000.

[10] OECD, Water: Performance and challenges in OECD countries, OECD: Paris, 2003.

[11] OECD, Improving water management. Recent OECD experience, OECD / IWA: Paris, 2003.

[12] World Water Assessment Programme. Valuing Water, www.unesco.org/water/wwap/

[13] PCE, Ageing pipes and murky waters. Urban water system issues for the 21st Century, Parliamentary Commissioner for the Environment: Wellington, 2000.

[14] Livingston, D.J., Stenekes, N., Colebatch, H.K., Ashbolt, N.J. \& Waite, T.D., Water recycling and decentralised management: the policy and organisational challenges for innovative approaches. Conference proceedings from WSUD 2004: Adelaide, 2004.

[15] Hardin, G., Tragedy of the commons. Science, 162, pp. 1243-1248, 1968.

[16] Tacconi, L., Biodiversity and ecological economics: participatory approaches to resources management, London: Earthscan Publications Ltd, 2000. 
[17] Burn, L., De Silva, D. \& Shipton, R., Effect of demand management and system operation on potable water infrastructure cost. Urban Water, 4, pp. 229-236, 2002.

[18] Kolokytha, E., Mylopoulus, Y. \& Mentes, A., Evaluation demand management aspects of urban water policy- A field survey in the city of Thessaloniki, Greece. Urban Water, 4, pp. 392-400, 2002.

[19] Nancarrow, B.E., Po, M., \& Porter, N.B., Why doesn't it work? The incorporation of community culture in the evaluation of Water Sensitive Urban Designs. Conference proceedings from WSUD 2004: Adelaide, 2004.

[20] Nauges, C., \& Thomas, A., Long-run study of residential water consumption (Chapter 2). Current issues in the economics of water resource management, eds. P. Pashardes, T. Swanson \& A. Xepapadeas, Kluwer Academic Publishers: Dordrecht, pp. 47-66, 2002.

[21] Thomas, J.F. \& Syme, G.J., Estimating residential price elasticity of demand for water: a contingent valuation approach. Water Resources Research, 24(11), pp. 1847-1857, 1988.

[22] Chapman, R., Goldberg, E., Salmon, G. \& Sinner, J., Sustainable development and infrastructure, The Ministry for Economic Development: Wellington, 2003.

[23] Craig, J., Science and sustainable development in New Zealand. Journal of the Royal Society of New Zealand, 34(1), 2004.

[24] Garcia, S. \& Reynard, A., Estimating the benefits of efficient water pricing in France. Resource and Energy Economics, 26, pp. 1-25, 2004.

[25] Kerr, G., Sharp, B. \& White, P., The economics of augmenting Christchurch's water supply. Journal of Hydrology (NZ), 42(2), pp. 113124, 2003.

[26] MfE, Sustainable development for New Zealand. Programme of action, Ministry for the Environment: Wellington, 2003.

[27] Quiggin, J., Environmental Economics and the Murray-Darling river system, Faculty of Economics and Commerce, Australian National University, 2000.

[28] OECD, The price of water: trends in OECD countries, OECD, 2000.

[29] O'Fallon, C., Linkages between infrastructure and economic growth, Ministry for Economic Development: Wellington, 2003.

[30] NZIER, Sustainable infrastructure: a policy framework, NZIER: Wellington, 2004.

[31] McLean, J., Aurora- delivering a sustainable urban water system for a new suburb. Conference proceedings from WSUD 2004: Adelaide, 2004.

[32] Raju, K.S., Duckstein, L. \& Arondel, C., Multicriterion analysis for sustainable water resources planning: a case study in Spain. Water Resources Management, 14, pp. 435-456, 2001.

[33] Holz, L., Kuczera, G.\& Kalma, J., Sustainable urban water planning in Australia: a decision science perspective. Conference proceedings from WSUD 2004: Adelaide, 2004. 
20 Environmental Economics and Investment Assessment II

[34] Forrester, J.W., Counterintuitive behaviour of system dynamics. Technology Review, 73(3), pp. 52-68, 1995.

[35] Constanza, R. \& Ruth, M., Modeling for scoping, research and management (Chapter 2). Institutions, ecosystems, and sustainability, eds. R. Constanza, B.S. Low, E. Ostrom \& J. Wilson J, CRC press LLC: Boca Raton, Florida, pp. 169-178, 2001.

[36] Richmond, B. Systems dynamics/systems thinking: let's just get on with it. International Systems Dynamics Conference: Stirling, Scotland, 1994. 